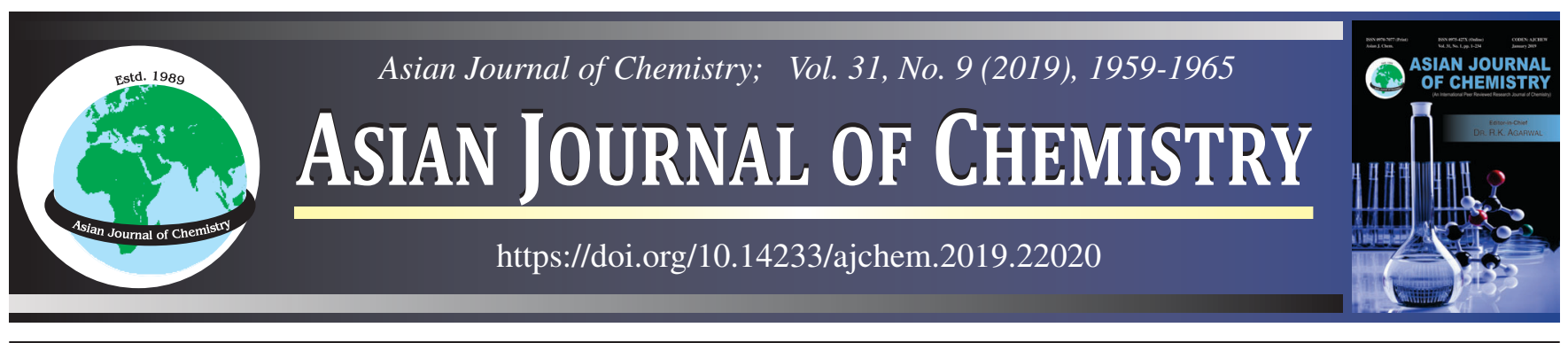

\title{
in silico Single Nucleotide Polymorphism Prediction and Design for Targeting Amyloid Precursor Protein in Alzheimers Disease
}

\author{
M. Meghna ${ }^{1}$, B. Athira ${ }^{1}$, T.S. Saranya ${ }^{1, *}$ and Asha Asokan Manakadan ${ }^{2, *},(0)$
}

${ }^{1}$ Department of Pharmaceutical Chemistry \& Analysis, Amrita School of Pharmacy, Amrita Vishwa Vidyapeetham, AIMS Health Science Campus, AIMS Ponekkara P.O. Kochi-682041, India

${ }^{2}$ Department of Pharmaceutical Chemistry, Nirmala College of Health Science, Nutmeg Gardens, Kunnappilly P.O. Chalakudy, Thrissur680311, India

*Corresponding authors: E-mail: saranyats19347@aims.amrita.edu; ashaasokan@ @irmalacollege.edu.in

Received: 22 February 2019

Accepted: 15 April 2019;

Published online: 31 July 2019;

AJC-19482

\begin{abstract}
Alzheimer's disease is a progressive neurodegenerative disorder, is the common cause of dementia and affect life quality. Present research analysis is based on the amyloid precursor protein as it is one of the major biomarkers of Alzheimer's disease, the insoluble part of which gets deposited due to the inappropriate cleavage by secretase enzyme. The instrumental part of this study was performed by using Computer Aided Drug Design (CADD). About 23 phytoconstituents were taken, from these constituents rosamarinic acid produced the highest docking score. Preliminary characterizations of all the ligands were conducted using Biovia Discovery studio along with protein characterization, Lipinski rule analysis and ADMET. The in silico analysis convincingly predicted the action of rosamarinic acid, against the formation of amyloid plaque by binding with the amyloid precursor protein .Details of single nucleotide polymorphism on gene APPI were analyzed by dbSNP database and displays the need for further in vitro study.
\end{abstract}

Keywords: Alzheimer, Amyloid protein, Biovia, docking, Secretase Enzyme, ProtParam.

\section{INTRODUCTION}

Alzheimer's disease is one among the neurodegenerative disorder, where the main setback is the loss of neurons in the hippocampus and basal fore brain. Among all the dementia cases reported Alzheimer's disease account for almost $60 \%$ [1]. According to world report on Alzheimer's disease, it is found that 35.6 million people suffer from this neurodegenerative disorder in 2010 and going on escalating to 67.57 million by 2030 [2].

It is mainly associated with brain shrinkage. They occur mainly at the age of 65 and above and then progress with age. Family history of dementia only plays a petite role. The two main marked microscopic features are extracellular amyloid plaques and intraneuronal neurofibrillary tangles [3-6]. Amyloid plaque is characterized by deposits of $\beta$-amyloid plaques and other with phosphorylated form of microtubule associated protein $[7,8]$. The erroneously processed amyloid peptide is the major contributory factor of this disease [6]. In normal circumstances amyloid precursor protein is being cleaved by $\alpha$-secretase into two parts, one which is the large soluble portion and the other being small membrane anchored part which is then cleaved by $\gamma$-secretase [9]. There is also an additional route of cleavage of amyloid precursor protein which is by $\beta$-secretase to produce the soluble fragment. But the problem arises when this is being cleaved by $\gamma$-secretase instead of $\beta$-secretase to produce less soluble amyloid $\beta$-peptides. The amyloid $\beta$-peptides now get to aggregate to produce the main character of Alzheimer's disease which is amyloidfibrils. This happens as the $\gamma$-secretase lacks precision and cut with varying lengths to form A $\beta-40$ and A $\beta-42$. Endosomal compartment witness the cleavage by $\beta$-secretase then $\alpha$-secretase pathway, while proteolysis by $\alpha$-secretase takes place in cell membrane. But there is still no evidence to suggest that Alzheimer's disease patients are dominated by $\beta$-secretase pathway. But the case is more likely be occurring due to the impaired clearance of fibrillogenic amyloid $\beta$-peptides [10]. The amyloid deposits are present in diseases other than Alzheimer's diseases which include Parkinsonism, senile systemic amyloidosis and even in type 2 diabetes mellitus [11].

Curcumin from Curcuma longa belonging to the ginger family was being used for centuries as a herbal medicine [12].

This is an open access journal, and articles are distributed under the terms of the Attribution 4.0 International (CC BY 4.0) License. This license lets others distribute, remix, tweak, and build upon your work, even commercially, as long as they credit the author for the original creation. You must give appropriate credit, provide a link to the license, and indicate if changes were made. 
It is found to have a promising effect on dementia therapy due its effectiveness as a antioxidant, anti-amyloidogenic and antiinflammatory actions [13,14]. Epigallocatechin gallate which is a flavanol obtained from Camellia sinensis due to its trihydro group in its $\mathrm{B}$ ring and the esterified gallate moiety in the $\mathrm{C}$ ring contribute to its antioxidant action $[15,16]$. Asiatic acid from Centella asiatica which is a triterpine have antioxidant and neuroprotective action. It helps in preventing mitochondrial membrane dysfunction and apoptosis [17]. Vincristine and vinblastine have antioxidant and also it arrest the cell division at metaphase and thus acting as an anticancer agent [18]. Withana somnifera contains withanolides and withaferin which helps in learning and memory improvement in Alzheimer's disease and they also affect the plaque pathology and reduces the load due to amyloid deposites [19]. Quercetin a flavanol helps in counteracting oxidative stress [20]. Linalool acts by reducing the histophathological hallmarks of Alzheimer's disease by affecting the inflammatory mediators and nonamyloidogenesis [21,22]. Kaempferol is found to have protective action on impaired performance due to amyloid peptides and oxidative stress inducing cell death [23]. Other phytoconstituents like butylated hydroxytoluene, myricetin, myristicin are also found to have antioxidant action [24]. The phytoconstituent rosamarinic acid belonging to the family laminacea is found to have antioxidant activity and inhibition of acetyl and butyryl cholinesterase that helps in the symptomatic relief in Alzheimer's disease. Now in this in silico studies prove that the rosamarinic aid is found to have inhibitory action on amyloid precursor protein [25]. Epigallocatechingallate is found to reduce the amyloid $\beta$-protein by cleaving the APP in the nonamyloidogenic pathway through the $\alpha$-secretase to produce soluble amyloid protein. It is found to have neuroprotective effect in the hippocampal pathway in case of neuronal damage with their action as ischemic induced increase in putrescine level [26-28]. In this study, the standard compound chosen are zinc and Congo red. Zinc is one of the essential trace element in the human biology and found to prevent the amyloid plaque generation in the brain cells. It is also being reported that the zinc reversibly block the amyloid poly-peptide. It is being previously reported [29] that amyloid plaques is able to form ion channel in the lipid layer and cause in the cell destruction. Thus study is made on the action of Congo red on the inhibition of this ion channel.

\section{EXPERIMENTAL}

Curcumin, kaempferol, anaferine, myricetin, butylated hydroxytoluene, rosmarinic acid, epigallocatechin, myristicin, linalool, withanolide A, withaferin A, ascorbic acid, withanolide $\mathrm{E}$, withanolide $\mathrm{D}, \beta$-sitosterol, quercetin, asiatic acid, campestrol, madecassic acid, vinblastine, vincristine, catharanthine and $\alpha$-pinene were the ligands used for the study. The phytoconstituent constituents with their IUPAC nomenclature are tabulated as Table-1. The information about the ligands, their 3D structure and canonomical smiles were collected from Pubchem, a chemical database and these were saved in PDB format. The 3D structure of phytoconstituents like kaempferol, curcumin, epigallocatechingallate, rosamarinic acid, myricetin that showed good binding energy is shown in Fig. 1.

The Biovia Discovery studio Version 2017 v 17.2.0.16349 was used for the characterization and depiction of ligands with its ADMET studies and the ADMET plot is drawn. Lipinski rule of five devised was used to subject the ligands for drug likeness for determining their structural and molecular properties. The rule formulated under Lipinski laid the following conditions for a ligand to be satisfactorily considered as a drug which include molecular weight to be less than $500 \mathrm{Da}$, lipophilicity not greater than 5 , hydrogen bond donors not less than 5, hydrogen bond acceptors not less than 5 [30-32]. Among the whole ligands taken about $90 \%$ ligands obey the criteria of Lipinski rule to be fulfilled as a drug. Amyloid precursor protein was selected as the target protein as being one of the main characteristic features of Alzheimer's disease in regions where memory and cognition are important. The structure of protein was collected from the RCSB protein data bank and the protein secondary characterization was done using secondary structure prediction method with alignment (SOPMA) which displays $\alpha$ - and $\pi$ - helix random coil [33]. Further then use ProtParam- a tool to analyze the primary structure $[34,35]$ and which includes the characterization using chemical and physical properties like aliphatic index, instability index, half life,

TABLE-1

IUPAC NAME OF PHYTOCONSTITUENTS WITH ANTI ALZHEIMERS ACTIVITY

\begin{tabular}{|c|c|}
\hline Chemical constituents & IUPAC nomenclature \\
\hline Curcumin & (1E,6E)-1,7-bis(4-Hydroxy-3-methoxyphenyl)hepta-1,6-diene-3,5-dione \\
\hline Kaempferol & 3,5,7-Trihydroxy-2-(4-hydroxyphenyl)chromen-4-one \\
\hline Anaferin & 1,3-bis[(2R)-Piperidin-2-yl]propan-2-one \\
\hline Butylated hydroxytoluene & 2,6-di-tert-Butyl-4-methylphenol \\
\hline Myricetin & 3,5,7-Trihydroxy-2-(3,4,5-trihydroxyphenyl)chromen-4-one \\
\hline Roamarinic acid & (2R)-3-(3,4-Dihydroxyphenyl)-2-[(E)-3-(3,4-dihydroxyphenyl)prop-2-enoyl]oxypropanoic acid \\
\hline Epigallocatechin & [(2R,3R)-5,7-Dihydroxy-2-(3,4,5-trihydroxyphenyl)-3,4-dihydro- $2 H$-chromen-3-yl]-3,4,5-trihydroxybenzoate \\
\hline Linalool & 3,7-Dimethylocta-1,6-dien-3-ol \\
\hline Myristicin & 3,5,7-Trihydroxy-2-(3,4,5-trihydroxyphenyl)chromen-4-one \\
\hline Withanolide A & (22R)-6 $\alpha, 7 \alpha$-Epoxy-5,20,22-trihydroxy-1-oxo-5 $\alpha$-ergosta-2,24-dien-26-oic acid $\delta$-lactone \\
\hline Withaferin A & $4 \beta, 5 \beta, 6 \beta, 22 \mathrm{R})$-5,6-Epoxy-4,22,27-trihydroxy-1-oxoergosta-2,24-dien-26-oic acid $\delta$-lactone \\
\hline Ascorbic acid & (2R)-2-[(1S)-1,2-Dihydroxyethyl]-3,4-dihydroxy-2H-furan-5-one \\
\hline Withanolide E & $(5 \beta, 6 \beta, 17 \alpha, 22 \mathrm{R})-14,17,20$-Trihydroxy-5,6:22,26-diepoxyergosta-2,24-diene-1,26-dione \\
\hline Withanolide D & 5,6-Epoxy-4,20,22-trihydroxy-1-oxoergosta-2,24-dien-26-oic acid $\delta$-lactone \\
\hline$\beta$-Sitosterol & $\begin{array}{l}\text { (3S,8S,9S,10R,13R,14S,17R)-17-[(2R,5R)-5-Ethyl-6-methylheptan-2-yl]-10,13-dimethyl- } \\
2,3,4,7,8,9,11,12,14,15,16,17 \text {-dodecahydro-1H-cyclopenta[a]phenanthren-3-ol }\end{array}$ \\
\hline
\end{tabular}



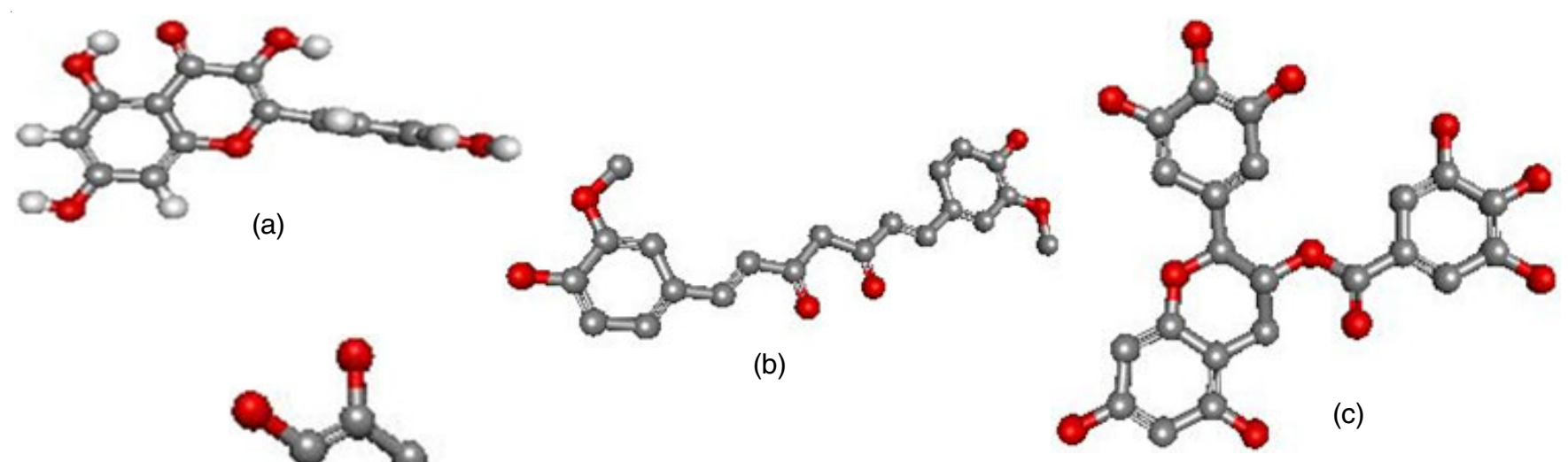

(d)

(b)
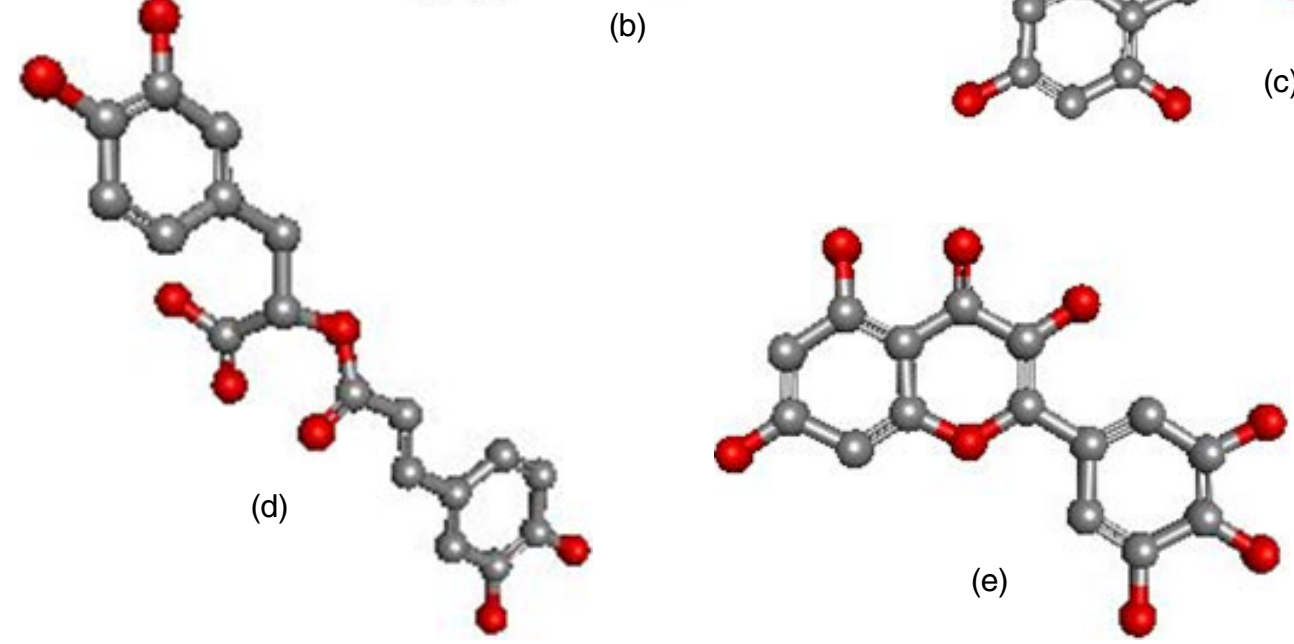

Fig. 1. Ball and stick representation of kaempferol (a), curcumin (b), epigallocaechingallate (c), rosamarinic acid (d) and myrsticin (e)

molecular weight and theoretical Pi. A protein is considered to be best when they satisfy high half life, low instability value with low $\alpha$-helix and moderately high $\beta$-turn. The proteins taken were 2LOH, 2LZ3 and 2LZ4 were subjected to primary and secondary characterization. The protein $2 \mathrm{LOH}$ with high half life, low instability value was selected for the study. The docking interactions protein was then subjected to cleaning procedure to remove the cells, water molecules and any hetero atoms and followed with docking procedures. Details of single nucleotide polymorphisms is obtained from online database dbSNP short genetic variations. Deleterious amino acid substitution prediction is done by SIFT tool [36-41] and POLYPHEN2 (polymorphism phenotyping $\mathrm{v} 2$ is a online tool narrates effects of amino acid substitution on the structure and function of protein) [42-44].

\section{RESULTS AND DISCUSSION}

Apart from the docking studies the preliminary characterization of all the ligands were also carried out using Biovia Discovery studio Version 2017 v 17.2.0.16349. Quality of ligands were calculated using ADMET studies and where successfully produced in Table-2.

Five constituents were found to cross the blood brain barrier viz., anaferin, butylated hydroxytoluene, rosamarinic acid, linalool and epigallocatechingallate. The study shows that all the ligands were found to be non-carcinogen and non-toxic in the AMES toxicity studies. Their ADMET plot is also produced in Fig. 2.

In the Lipinski rule characterization, it was found that $\beta$-sitosterol, medecassic acid and vincristine desecrated the law with molecular weight greater than 500 Dalton and in case of TPSA parameter, epigallocatechin gallate and vincristine

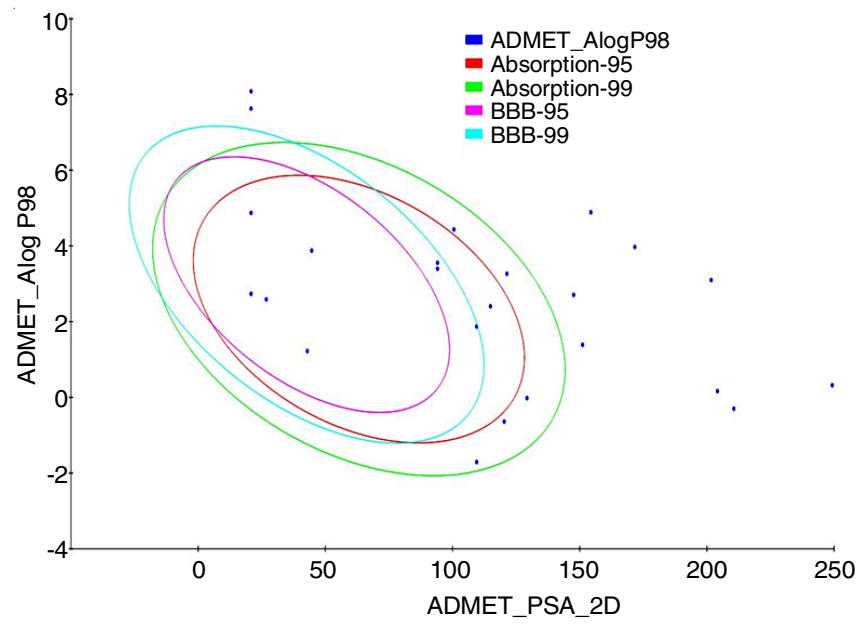

Fig. 2. ADMET plot of 23 ligands

disobey it with TPSA value greater than 160 . Along with this $\beta$-sitosterol have a lipophilicity value greater than 5 thus violating the drug likeliness (Table-3).

3D structure of both ligand and protein where displayed using Biovia for docking course of action to be carried out with high efficiency. The opening studies for the research study about the ligands and targets where conducted. Initially three protein with ID No. 2LOH, 2LZ3, 2LZ4 were taken. From these 3 , the protein for the docking study was selected based on their characters using Protparam (Table-4) and SOPMA tools (Table-5).

The favoured one was $2 \mathrm{LOH}$ as it possess low $\alpha$-helix and high random coil and further having long half life of $30 \mathrm{~h}$. In addition, it was very much stable than the other two. Twenty four ligands where made to dock with three sites in the protein. 
TABLE-2

ADMET STUDIES OF THE PHYTOCONSTITUENTS AND STANDARD DRUG

\begin{tabular}{|c|c|c|c|c|c|c|c|c|}
\hline \multirow{2}{*}{ Ligands } & \multirow{2}{*}{$\mathrm{BBB}$} & \multirow{2}{*}{ HIA } & \multicolumn{4}{|c|}{ CYP Inhibitor } & \multirow{2}{*}{$\begin{array}{l}\text { AMES } \\
\text { toxicity }\end{array}$} & \multirow{2}{*}{ Carcinogenicity } \\
\hline & & & CYP1A2 & CYP2C9 & CYP2D6 & CYP3A4 & & \\
\hline Curcumas & 0.6162 & 0.9539 & Inhibit & Inhibit & Inhibit & Non-inhibit & Non-toxic & Non-carcinogen \\
\hline Kaempferol & 0.628 & 0.98 & Inhibit & Inhibit & Non-inhibit & Inhibit & Non-toxic & Non-carcinogen \\
\hline Anaferin & 0.941 & 0.9234 & Non-inhibit & Non-inhibit & Non-inhibit & Non-inhibit & Non-toxic & Non-carcinogen \\
\hline Butylated hydroxytoluene & 0.95 & 0.9941 & Inhibit & Non-inhibit & Non-inhibit & Non-inhibit & Non-toxic & Non-carcinogen \\
\hline Myricetin & 0.5711 & 0.965 & Inhibit & Non-inhibit & Non-inhibit & Inhibit & Non-toxic & Non-carcinogen \\
\hline Roamarinic acid & 0.577 & 0.965 & Inhibit & Non-inhibit & Non-inhibit & Inhibit & Non-toxic & Non-carcinogen \\
\hline Epigallocatechingallate & 0.60 & 0.88 & Non-inhibit & Non-inhibit & Non-inhibit & Non-inhibit & Non-toxic & Non-carcinogen \\
\hline Linalool & 0.99 & 0.97 & Non-inhibit & Non-inhibit & Non-inhibit & Non-inhibit & Non-toxic & Non-carcinogen \\
\hline Myristicin & 0.9504 & 0.994 & Inhibit & Inhibit & Inhibit & Inhibit & Non-toxic & Non-carcinogen \\
\hline Withanolide A & 8.327 & 0.895 & Non-inhibit & Non-inhibit & Non-inhibit & Non-inhibit & Non-toxic & Non-carcinogen \\
\hline Withaferin A & 0.869 & 0.808 & Non-inhibit & Non-inhibit & Non-inhibit & Non-inhibit & Non-toxic & Non-carcinogen \\
\hline Ascorbic acid & 0.8532 & 0.6559 & Non-inhibit & Non-inhibit & Non-inhibit & Non-inhibit & Non-toxic & Non-carcinogen \\
\hline Withanolide E & 0.610 & 0.618 & Non-inhibit & Non-inhibit & Non-inhibit & Non-inhibit & Non-toxic & Non-carcinogen \\
\hline Withanolide D & 0.7979 & 0.8736 & Non-inhibit & Non-inhibit & Non-inhibit & Non-inhibit & Non-toxic & Non-carcinogen \\
\hline$\beta$-Sitosterol & 0.694 & 0.878 & Non-inhibit & Non-inhibit & Non-inhibit & Non-inhibit & Non-toxic & Non-carcinogen \\
\hline Quercetin & 0.577 & 0.96 & Inhibit & Non-inhibit & Non-inhibit & Inhibit & Non-toxic & Non-carcinogen \\
\hline Asiatic acid & 0.74 & 0.94 & Non-inhibit & Non-inhibit & Non-inhibit & Non-inhibit & Non-toxic & Non-carcinogen \\
\hline Campesterol & 0.97 & 1 & Non-inhibit & Non-inhibit & Non-inhibit & Non-inhibit & Non-toxic & Non-carcinogen \\
\hline Madecassic acid & 0.74 & 0.94 & Non-inhibit & Non-inhibit & Non-inhibit & Non-inhibit & Non-toxic & Non-carcinogen \\
\hline Vincristine & 0.95 & 0.97 & Non-inhibit & Non-inhibit & Non-inhibit & Non-inhibit & Non-toxic & Non-carcinogen \\
\hline Vinblastine & 0.9203 & 0.9806 & Non-inhibit & Non-inhibit & Non-inhibit & Non-inhibit & Non-toxic & Non-carcinogen \\
\hline Catheranthine & 0.9452 & 0.9918 & Non-inhibit & Non-inhibit & Non-inhibit & Inhibit & Inhibit & Non-carcinogen \\
\hline$\alpha$-Pinene & 0.89 & 0.996 & Non-inhibit & Non-inhibit & Non-inhibit & Non-inhibit & Non-toxic & Non-carcinogen \\
\hline Zinc & 0.9733 & 0.9838 & Non-inhibit & Non-inhibit & Non-inhibit & Non-inhibit & Non-toxic & Carcinogen \\
\hline Congo red & 0.753 & 0.921 & Non-inhibit & Non-inhibit & Non-inhibit & Non-inhibit & Toxic & Carcinogen \\
\hline
\end{tabular}

$\mathrm{BBB}=$ Blood brain barrier; HIA = Human intestinal absorption

TABLE-3

EVALUATION OF THE DRUG LIKENESS OF THE HERBAL CONSTITUENTS

\begin{tabular}{|c|c|c|c|c|c|c|c|c|c|}
\hline S. No. & Chemical constituents & $\operatorname{miLog} \mathrm{P}$ & TPSA & natoms & m.w. & $\mathrm{nOH}$ & $\mathrm{nOHNH}$ & nrotb & Volume \\
\hline 1 & Curcumin & 2.30 & 93.07 & 27 & 36.38 & 6 & 2 & 8 & 332.18 \\
\hline 2 & Kaempferol & 2.17 & 111.12 & 21 & 286.14 & 6 & 4 & 1 & 232.07 \\
\hline 3 & Anaferin & 1.38 & 41.12 & 16 & 224.34 & 3 & 2 & 4 & 236.41 \\
\hline 4 & Butylated hydroxytoluene & 5.43 & 20.23 & 16 & 220.36 & 1 & 1 & 2 & 241.00 \\
\hline 5 & Myricetin & 1.39 & 151.58 & 23 & 318.24 & 8 & 6 & 1 & 248.10 \\
\hline 6 & Roamarinic acid & 1.63 & 144.32 & 26 & 360.32 & 8 & 5 & 7 & 303.54 \\
\hline 7 & Epigallocatechin & 2.25 & 197.36 & 33 & 458.38 & 11 & 8 & 4 & 367.57 \\
\hline 8 & Linalool & 2.43 & 20.23 & 10 & 140.23 & 1 & 1 & 4 & 159.03 \\
\hline 9 & Myristicin & 2.44 & 27.7 & 14 & 192.21 & 3 & 0 & 3 & 178.05 \\
\hline 10 & Withanolide A & 4.15 & 96.36 & 34 & 470.61 & 6 & 2 & 2 & 441.81 \\
\hline 11 & Withaferin A & 3.86 & 6.36 & 34 & 470.61 & 6 & 2 & 3 & 442.38 \\
\hline 12 & Ascorbic acid & -1.40 & 107.22 & 12 & 176.12 & 6 & 4 & 2 & 13.71 \\
\hline 13 & Withanolide E & 3.18 & 116.59 & 35 & 486.71 & 7 & 3 & 2 & 449.16 \\
\hline 14 & Withanolide D & 4.15 & 96.36 & 34 & 470.61 & 6 & 2 & 2 & 441.84 \\
\hline 15 & Beta sitosterol & 7.15 & 99.38 & 41 & 576.86 & 6 & 4 & 9 & 588.64 \\
\hline 16 & Quercetin & 1.68 & 131.35 & 22 & 302.24 & 7 & 5 & 1 & 240.08 \\
\hline 17 & Asiatic acid & 4.70 & 97.98 & 35 & 488.71 & 5 & 4 & 2 & 487.79 \\
\hline 18 & Campesterol & 8.30 & 20.23 & 29 & 400.69 & 1 & 1 & 5 & 439.70 \\
\hline 19 & Madecassic acid & 3.78 & 118.21 & 36 & 504.21 & 6 & 5 & 2 & 495.83 \\
\hline 20 & Vincristine & 4.95 & 171.18 & 60 & 824.97 & 14 & 3 & 10 & 747.07 \\
\hline 21 & Vinblastine & 5.56 & 154.11 & 59 & 810.99 & 13 & 3 & 3 & 744.65 \\
\hline 22 & Catharanthine & 3.99 & 45.33 & 25 & 336.44 & 4 & 1 & 3 & 315.99 \\
\hline \multicolumn{10}{|c|}{ Standard drug } \\
\hline 1 & Zinc & -0.39 & 0 & 1 & 65.39 & 0 & 0 & 0 & 40.59 \\
\hline 2 & Congo red & 3.90 & 215.09 & 46 & 650 & 12 & 4 & 7 & 520.25 \\
\hline
\end{tabular}

TPSA: Total polar surface area, m.w.: Molecular weight, nON: Number of hydrogen bond acceptors, natoms: Number of atoms, nOHNH: Number of hydrogen bond donors, nrotb: Number of rotatable bonds. 


\begin{tabular}{cccccc}
\hline \multicolumn{5}{c}{ TABLE-4 } \\
SECONDARY CHARACTERIZATION OF PROTEIN USING SOPMA \\
\hline S. No. & PDB ID & Alpha helix & Pi helix & Random coil & $\beta$-Turn \\
\hline 1 & 2 LZ3 & 21 & 0 & 2 & 10 \\
2 & $2 \mathrm{LZ4}$ & 31 & 0 & 3 & 18 \\
3 & 2LOH & 8 & 0 & 18 & 12 \\
\hline
\end{tabular}

\begin{tabular}{cccccccc}
\multicolumn{7}{c}{ TABLE-5 } \\
\multicolumn{7}{c}{ PRIMARY CHARACTERIZATION OF PROTEIN USING ProtParam } \\
\hline S. No. & PDB ID & No of amino acids & Theoretical pi & m.w. & Instability index & Aliphatic index & Half life \\
\hline 1 & 2LZ3 & 62 & 10.85 & 6260.17 & 4.11 & 169.68 & 4.4 \\
2 & 2LZ4 & 62 & 10.5 & 6324.29 & 4.11 & 160.32 & 4.4 \\
3 & 2LOH & 86 & 10 & 8872.93 & 12.43 & 142.56 & 30 \\
\hline
\end{tabular}

About 7 constituents showed the required action with an increased docking energy than the standard one. This is represented in a graph. The docking analysis was tabulated with their different docking scores at the three sites and specified in Table-6.

And it was finalized to be rosamarinic acid with the highest CDocker value and with all needed properties. This was then compared with the standard on zinc and Congo red and found to have higher value. In addition, in the preliminary screening of the standard one Congo red and zinc was found to be carcinogen. The docking of protein $2 \mathrm{LOH}$ with rosamarinic acid is shown in Fig. 3 and their chemical interaction with various amino acid involved is visualized in Fig. 4. Finally, a graph was plotted with the docking score at the three sites as shown in Fig. 5.

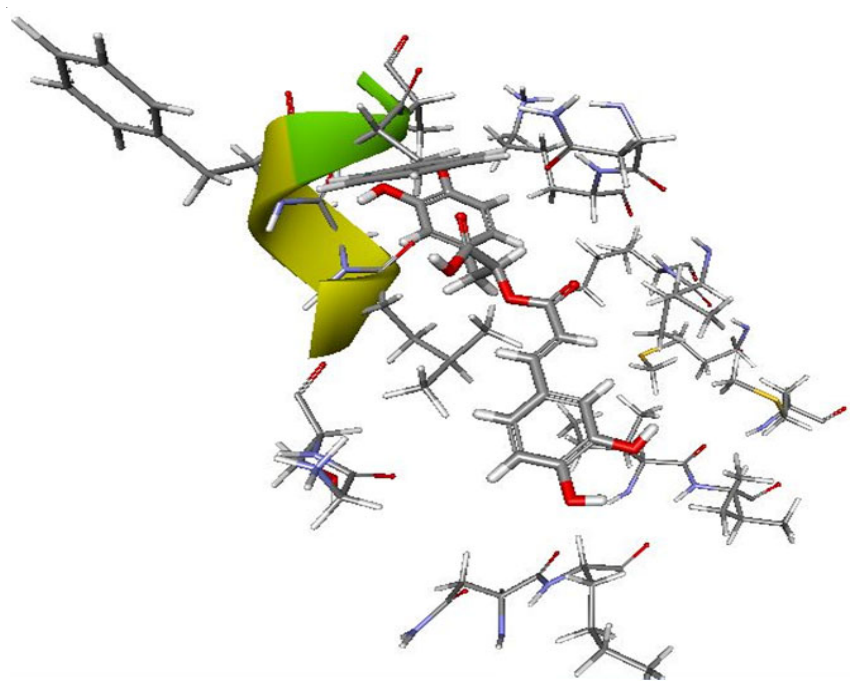

Fig. 3. Docking of protein with PDB ID: 2LOH with rosamarinic acid

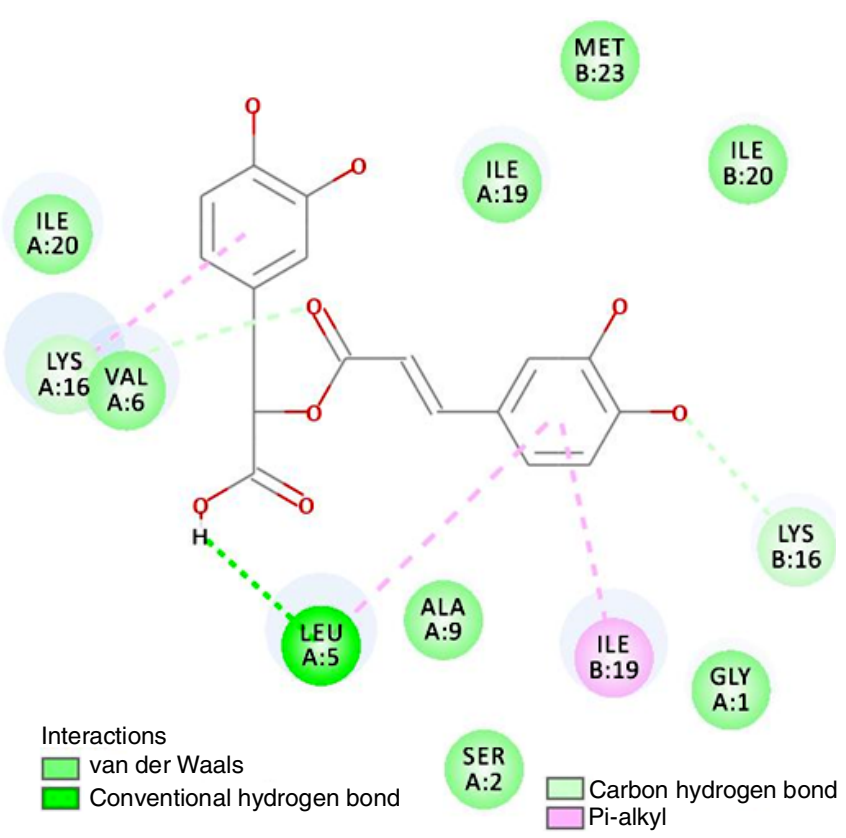

Fig. 4. Docking with the interactions and amino acid involved

Mutations in critical regions of amyloid precursor protein, including the region that generates amyloid beta $(A \beta)$, cause familial susceptibility to Alzheimer's disease [45-47]. Single nucleotide polymorphisms associated with amyloid precursor protein gene APPI was found to be 71529 . From this total SNPs, 486 covers the missense mutation and 241 count to be coding synonymous. 5'utr and 3'utr region containing 188 and 334 SNPs, respectively. Nonsense SNPs are 10 and frame shift SNPs are 9. From polyphen data, found that only $2 \mathrm{rs} \mathrm{id}$ cause probably damaging are 1800557 and 5588932. Cause of

\begin{tabular}{|c|c|c|c|c|c|c|}
\hline \multicolumn{7}{|c|}{$\begin{array}{c}\text { TABLE-6 } \\
\text { DOCKING SCORE AT THREE DIFFERENT SITES }\end{array}$} \\
\hline \multirow[b]{2}{*}{ Chemical constituents } & \multicolumn{2}{|c|}{ Site 1} & \multicolumn{2}{|c|}{ Site 2} & \multicolumn{2}{|c|}{ Site 3} \\
\hline & $\begin{array}{c}\text {-CD Docker } \\
\text { energy } \\
(\mathrm{kcal} / \mathrm{mol})\end{array}$ & $\begin{array}{l}\text {-CD interaction } \\
\text { energy }\end{array}$ & $\begin{array}{c}\text {-CD Docker } \\
\text { energy } \\
(\mathrm{kcal} / \mathrm{mol})\end{array}$ & $\begin{array}{l}\text {-CD interaction } \\
\text { energy }\end{array}$ & $\begin{array}{c}\text {-CD Docker } \\
\text { energy } \\
(\mathrm{kcal} / \mathrm{mol})\end{array}$ & $\begin{array}{l}\text {-CD interaction } \\
\text { energy }\end{array}$ \\
\hline Kaempferol & 20.52 & 25.42 & 25 & 31 & 16.2 & 21 \\
\hline Curcumn & 18.58 & 28.24 & 24 & 33.08 & 19 & 28 \\
\hline Epigallocatechingallate & 25.81 & 27.35 & 25.9 & 27.2 & 27.3 & 28.8 \\
\hline Myricetin & 19.9 & 20.41 & 23 & 25 & 20.9 & 21.5 \\
\hline Anaferin & 6.04 & 22.37 & - & - & - & - \\
\hline Butylated hydroxytoluene & 4.9 & 16.25 & - & - & - & - \\
\hline Rosamarinic acid & - & - & 32 & 32 & 29.4 & 32 \\
\hline
\end{tabular}


TABLE-7

SINGLE NUCLEOTIDE POLYMORPHISM, SIFT PREDICTION

\begin{tabular}{cccccc}
\hline SNP & Amino acid change & SIFT score & SIFT median & No. of SEQS at position & SIFT prediction \\
\hline rs63750264 & V717F & 0.001 & 2.48 & 101 & Deleterious \\
rs63750264 & V642F & 0.001 & 2.43 & 101 & Deleterious \\
rs1800557 & A713V & 0.001 & 2.48 & 100 & Deleterious \\
rs1800557 & A695V & 0.001 & 2.52 & 87 & Deleterious \\
rs63750579 & E674Q & 0.022 & 2.59 & 88 & Deleterious \\
rs63750579 & E669Q & 0.022 & 2.63 & 101 & Deleterious \\
rs63749964 & V717G & 0 & 2.48 & 101 & Deleterious \\
rs63749964 & V642G & 0 & 2.43 & 100 & Deleterious \\
rs63750066 & A638T & 0.002 & 2.43 & & Deleterious \\
\hline
\end{tabular}

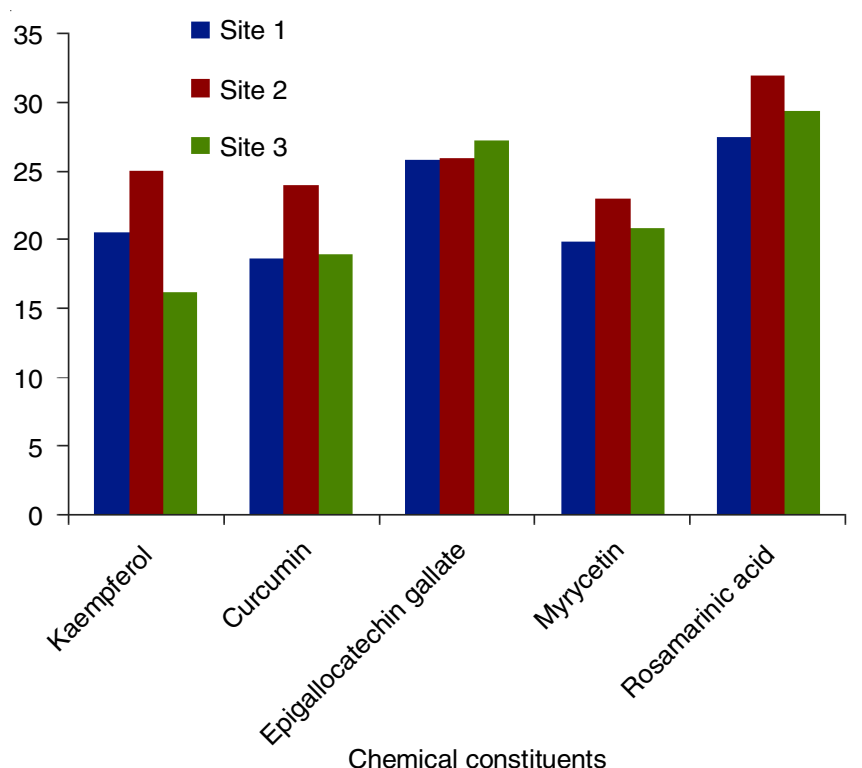

Fig. 5. Graph of docking score of phytoconstituents at 3 different sites

damaging is due to change in amino acid at a particular position. At 713 position alanine change to lysine cause rs id 1800557 leads to probably damaging and glutamic acid change to lysine at 501 position leads to probably damaging of rs id 5588932 .

From the SIFT online tool, SIFT score ranges from 0 to 1. The amino acid substitution is predicted damaging is the score is $<=0.05$, and tolerated if the score is $>0.05$. Sift median ranges from 0 to 4.32 , ideally the number would be between 2.75 and 3.5. This is used to measure the diversity of sequences used for prediction. A warning will occur if this is greater than 3.25 because this indicates that the prediction was based on closely related sequences. Sequence at position is the number of sequences that have an amino acid at the position of prediction. Substitution at position 717 from valine to phenylalanine predicted to be deleterious. Result of SIFT online tool details are specified in Table-7.

\section{Conclusion}

The CADD analysis was very helpful in predicting the ideal characteristics of both the protein and the ligands and aided in highlighting the useful phytoconstituents for diseases. All the conventional therapies for Alzheimer's disease produce only symptomatic relief and neither of them affects the amyloid plaque formation thus this study is a major break through for this treatment. From the in silico analysis, it was concluded that rosamarinic acid was useful to act against amyloid precursor protein to prevent its redundant cleavage by the secretase enzyme into amyloid plaque further assisting in the neuroprotective effect in Alzheimer's disease. Additionally this compound obeys all the rules to show the drug likeliness behaviour under the Lipinski rule. The phytoconstituent also shows more drug docking score than the standard compounds zinc and Congo red with the same mechanism of action. Now, it sets a new path to find out through the in vitro studies in future.

\section{CONFLICT OF INTEREST}

The authors declare that there is no conflict of interests regarding the publication of this article.

\section{REFERENCES}

1. C. Holmes, Medicine J., 40, 628 (2012); https://doi.org/10.1016/j.mpmed.2012.08.012.

2. A. Wimo, L. Jönsson, J. Bond, M. Prince and B. Winblad, Alzheimers Dement., 9, 1 (2013); https://doi.org/10.1016/j.jalz.2012.11.006.

3. A.M. Asha, T.S. Saranya, K.S. Silvipriya and J. Chithra, Res. J. Pharm. Biol. Chem. Sci., 6, 414 (2015).

4. K.U. Radhagayathri, P.K.K. Namboori, V.P. Mohandas, T. Subeesh, D. Gopakumar and K.I. Ramachandran, Int. J. Nanosci., 10, 319 (2011); https://doi.org/10.1142/S0219581X11008010.

5. M. Ratnaprava, Univ. J. Ayur. Herb Med., 4, 9 (2016).

6. R. Thomas, R. Hari, J. Joy, S. Krishnan, A.N. Swathy, S.S. Nair, A.A. Manakadan, Sathianarayanan and T.S. Saranya, Res. J. Pharm. Tech., 8, 1673 (2015); https://doi.org/10.5958/0974-360X.2015.00302.9.

7. T. Sobow, M. Flirski and P.P. Liberski, Acta Neurobiol. Exp., 64, 53 (2004).

8. X. Sun, W. Dong, Y. Chan and Y.D. Wang, Front. Pharmacol., 6, 221 (2015);

https://doi.org/10.3389/fphar.2015.00221

9. X.X. Wang, M.S. Tan, J.T. Yu and L. Tan, BioMed. Res. Int., 2012, Article ID 908636 (2014); https://doi.org/10.1155/2014/908636.

10. I. Hussain, D. Powell, D.R. Howlett, D.G. Tew, T.D. Meek, C. Chapman, I.S. Gloger, K.E. Murphy, C.D. Southan, D.M. Ryan, T.S. Smith, D.L. Simmons, F.S. Walsh, C. Dingwall and G. Christie, Mol. Call. Neuosci., 14, 419 (1999); https://doi.org/10.1006/mcne.1999.0811.

11. M.S. Parihar and T. Hemnani, J. Clin. Neurosci., 11, 456 (2004); https://doi.org/10.1016/j.jocn.2003.12.007.

12. F. Chiti and C.M. Dobson, Anal. Rev. Biochem., 75, 333 (2006); https://doi.org/10.1146/annurev.biochem.75.101304.123901.

13. H. Hatcher, R. Planalp, J. Cho, F.M. Torti and S.V. Torti, Cell. Mol. Life Sci., 65, 1631 (2008); https://doi.org/10.1007/s00018-008-7452-4.

14. G.M. Cole, B. Teter and S.A. Frautschy, Adv. Exp. Med. Biol., 595, 197 (2007);

https://doi.org/10.1007/978-0-387-46401-5_8. 
15. M. Waseem and S. Parvez, Protoplasma, 253, 417 (2016); https://doi.org/10.1007/s00709-015-0821-6.

16. S. Davinelli, N. Sapere, D. Zella, R. Bracale, M. Intrieri and G. Scapagnini, Oxid. Med. Cell Longev., 2012, Article ID 386527 (2012); https://doi.org/10.1155/2012/386527.

17. K. Chandrasekaran, Z. Mehrabian, B. Spinnewyan, K. Drieu and G. Fiskum, Pharmacogn. Rev., 6, 81 (2012); https://doi.org/10.4103/0973-7847.99898.

18. K. Chandrasekaran, Z. Mehrabian, B. Spinnewyn, K. Drieu and G. Fiskum, Brain Res., 922, 282 (2001); https://doi.org/10.1016/S0006-8993(01)03188-2

19. R.H. Zhu, H.D. Li, H.L. Cai, Z.P. Jiang, P. Xu, L.B. Dai and W.X. Peng, J. Pharm. Biomed. Anal., 96, 31 (2014); https://doi.org/10.1016/j.jpba.2014.03.017.

20. M.A. Rather, A.J. Thenmozhi, T. Manivasagam, J. Nataraj, M.M. Essa and S.B Chidambaram, Front. Biosci., 10, 287 (2018); https://doi.org/10.2741/e823.

21. N. Sehgal, A. Gupta, R.K. Valli, S.D. Joshi, J.T. Mills, E. Hamel, P. Khanna, S.C. Jain and S.S. Thakur, Proc. Natl. Acad. Sci. USA, 109, 3510 (2012); https://doi.org/10.1073/pnas.1112209109.

22. T. Lin and M.F. Beal, Nature, 443, 787 (2006); https://doi.org/10.1038/nature05292.

23. A.M. Sabogal-Guaqueta, E. Osorio and G.P. Cardona-Gomez, $J$. Neuropharm., 102, 111 (2016); https://doi.org/10.1016/j.neuropharm.2015.11.002.

24. J.K. Kim, S.J. Choi, H.Y. Cho, H.J. Hwang, Y.J Kim, S.T. Lim, C.J. Kim, H.K. Kim, S. Peterson and D.H. Shin, Biosci. Biotechnol. Biochem., 74, 397 (2010). https://doi.org/10.1271/bbb.90585.

25. A. Rajendran, S. Martin, R. Eso, A.A. Manakadan and T.S. Saranya, J. Pharm. Sci. Res., 9, 1117 (2017).

26. M. Akram and A. Nawaz, Neural Regen Res., 12, 660 (2017); https://doi.org/10.4103/1673-5374.205108.

27. M. Ozarowski, P.L. Mikolajczak, A. Bogacz, R. Kujawski and P.M. Mrozikiewicz, Herba Polonica, 56, 91 (2010).

28. C.L. Lin, T.F. Chen, M.J. Chiu, T.D. Way and J.K. Lin, Neurobiol. Aging, 30, 81 (2009); https://doi.org/10.1016/j.neurobiolaging.2007.05.012.

29. M. He, M.J. Zhao, M.-J. Wei, W.-F. Yao, H.-S. Zhao and F.-J. Chen, Biol. Pharm. Bull., 32, 55 (2009); https://doi.org/10.1248/bpb.32.55.

30. M.R. Wilkins, E. Gasteiger, A. Bairoch, J.C. Sanchez, K.L. Williams, R.D. Appel and D.F. Hochstrasser, ed.: A.J. Link, Protein Identification and Analysis Tools in the ExPASy Server. 2-D Proteome Analysis Protocols, In: Methods in Molecular Biology, Humana Press, vol 112 (1999).
31. C.A. Lipinski, F. Lombardo, B.W. Dominy and P.J. Feeney, Adv. Drug Deliv. Rev., 23, 3 (1997); https://doi.org/10.1016/S0169-409X(96)00423-1.

32. C.A. Lipinski, J. Pharmacol. Toxicol. Methods, 44, 235 (2000); https://doi.org/10.1016/S1056-8719(00)00107-6.

33. Y. Hirakura, W.W. Yiu, A. Yamamoto and B.L. Kagan, Amyloid, 7, 194 (2000); https://doi.org/10.3109/13506120009146834.

34. C. Geourjon and G. Deleage, Comput. Appl. Biosci., 11, 681 (1996).

35. S.G. Gayathri, V. Vishnu, S. Shibu, T.S. Saranya and A.M. Asha, J. Chem. Pharm. Res., 7, 170 (2015).

36. P. Kumar, S. Henikoff and P.C. Ng, Nat. Protoc., 4, 1073 (2009); https://doi.org/10.1038/nprot.2009.86.

37. P.C. Ng and S. Henikoff, Genome Res., 11, 863 (2001); https://doi.org/10.1101/gr.176601.

38. P.C. Ng and S. Henikoff, Genome Res., 12, 436 (2002); https://doi.org/10.1101/gr.212802.

39. P.C. Ng and S. Henikoff, Nucleic Acids Res., 31, 3812 (2003); https://doi.org/10.1093/nar/gkg509.

40. I.A. Adzhubei, S. Schmidt, L. Peshkin, V.E. Ramensky, A. Gerasimova, P. Bork, A.S. Kondrashov and S.R. Sunyaev, Nat. Methods, 7, 248 (2010); https://doi.org/10.1038/nmeth0410-248

41. V. Ramensky and P.B.S. Sunyaev, Nucleic Acids Res., 30, 3894 (2002); https://doi.org/10.1093/nar/gkf493.

42. I. Adzhubei, M. Daniel and R. Jordan, Curr. Protoc. Hum. Genet., 7, 1 (2013)

43. I.A. Adzhubei, S. Schmidt, L. Peshkin, V.E. Ramensky, A. Gerasimova, P. Bork, A.S. Kondrashov and S.R. Sunyaev, Nat. Methods, 7, 248 (2010); https://doi.org/10.1038/nmeth0410-248.

44. S. Hicks, D.A. Wheeler, S.E. Plon and M. Kimmel, Hum. Mutat., 32, 661 (2011); https://doi.org/10.1002/humu.21490.

45. H. Zheng and E.H. Koo, Mol. Neurodegener., 1, 5 (2006); https://doi.org/10.1186/1750-1326-1-5.

46. A. Goate, M.C. Chartier-Harlin, M. Mullan, J. Brown, F. Crawford, L. Fidani, L. Giuffra, A. Haynes, N. Irving, L. James, R. Mant, P. Newton, K. Rooke, P. Roques, C. Talbot, M. Pericak-Vance, A. Roses, R. Williamson, M. Rossor, M. Owen and J. Hardy, Nature, 349, 704 (1991); https://doi.org/10.1038/349704a0.

47. J. Murrell, M. Farlow, B. Ghetti and M.D. Benson, Science, 254, 97 (1991); https://doi.org/10.1126/science.1925564. 